\title{
¿Existen en Chile procedimientos administrativos que presentan, también, una naturaleza jurisdiccional?
}

\author{
Are there administrative procedures that also have \\ a jurisdictional nature in Chile? \\ CLAUDIO MORAGA KLENNER*
}

\begin{abstract}
Resumen: Las funciones administrativas y jurisdiccionales no son identificables en modo alguno. Los órganos de la administración actúan por regulaciones administrativas que no tienen, al mismo tiempo, una naturaleza jurisdiccional. Ello, sin embargo, no excluye la posibilidad de que, en casos muy excepcionales, ciertos órganos administrativos ejerzan jurisdicción, pero entonces la función es ejercida conforme a reglas jurisdiccionales que no son administrativas.

Palabras clave: Órganos administrativos - función jurisdiccional

Summary: Administrative and jurisdictional functions can not be identifiable (equivalent) in any way. Administration bodies act by administrative regulations and do not have, at the same time, a jurisdictional nature. However, in exceptional cases, the possibility for some administrative bodies to exercise jurisdiction can not be excluded; but in that case, this function is exercised according to jurisdictional rules, not administrative ones.
\end{abstract}

Key words: Administrative bodies - jurisdictional function

CONTENIDO: INTRODUCCIÓN. - I. LA ORGANIZACIÓN DEL ESTADO. II. FUNCIÓN ADMINISTRATIVA. - III. FUNCIÓN JURISDICCIONAL. - IV. LA CUESTIÓN ADJETIVA: EL NÚCLEO MATERIAL Y PROCEDIMENTAL DEL PROCEDIMIENTO ADMINISTRATIVO GENERAL. - V. PROCEDIMIENTOS ADMINISTRATIVOS DE PRIMER GRADO: DE TIPO SANCIONATORIOS, EL DEBIDO PROCESO Y LA NEGACIÓN DE LAS POTESTADES RESOLUTIVAS DE LA ADMINISTRACIÓN. VI. PROCEDIMIENTOS ADMINISTRATIVOS DE SEGUNDO GRADO: LA CONFUSIÓN RESPECTO DE SI LA VÍA RECURSIVA ANTE LA PROPIA ADMINISTRACIÓN TIENE O NO NATURALEZA JURISDICCIONAL. - VII. CASOS PACÍFICOS DE ÓRGANOS ADMINISTRATIVOS QUE EJERCEN JURISDICCIÓN. - VII.1. ÓRGANOS ADMINISTRATIVOS QUE PUEDEN ACTUAR COMO ÁRBITROS ARBITRADORES. VII.2. LA CGR Y EL JUICIO DE CUENTAS.- VIII. CONCLUSIONES.

* Es abogado magister rerum publicarum y profesor asociado de Derecho administrativo en la Facultad de Derecho de la Universidad de Chile. Correo electrónico: cmoraga@eml.cl. 


\section{INTRODUCCIÓN}

La interrogante del título debe ser respondida con una negativa: sea por la función, por las reglas que someten el ejercicio del poder público o por organización, no es posible identificar un procedimiento administrativo que, a un mismo tiempo, sea de tipo jurisdiccional.

Con todo, el tema es complejo. En primer lugar, porque no es posible negar de modo absoluto que los órganos administrativos no puedan ejercer jurisdicción en casos muy especiales - verbigracia, el juicio de cuentas y la Contraloría General de la República (CGR)—. En segundo lugar, porque cuando aquel órgano ejerce función jurisdiccional expresamente reconocida por el orden jurídico, en realidad actúa como órgano jurisdiccional y no como administrativo. En tercer lugar, porque existen procedimientos administrativos que, sin embargo, han sido calificados por los propios tribunales de justicia como de naturaleza jurisdiccional — sin verdaderamente serlos-.

Por todo lo anterior, pareciera ser necesario comenzar por revisar la organización del Estado en Chile y explicar las diferencias entre la función administrativa y la jurisdiccional.

\section{LA ORGANIZACIÓN DEL ESTADO}

Todas las funciones estatales, independiente de su denominación y naturaleza, se justifican en cuanto permiten al Estado servir a la persona humana, y en tanto promueven el bien común —entendido este como el deber que pesa en él de «crear las condiciones sociales que permitan a todos y a cada uno de los integrantes de la comunidad nacional su mayor realización espiritual y material posible, con pleno respeto a los derechos y garantías que esta Constitución establece» ${ }^{1}$.

En el cumplimiento de tan grande tarea constitucional, se ha confiado el gobierno y la administración del Estado al Poder Ejecutivo, a lo que la Constitución Política de la República (CPR) designa como «gobierno» en su artículo 24. A su vez, la función legislativa ha sido otorgada concurrentemente tanto al presidente de la república como a las ramas del congreso nacional — senado y cámara de diputados—, según los artículos 32, numeral 1 y 46 . Finalmente, el ejercicio de la función jurisdiccional se ha confiado a los tribunales establecidos por la ley, de acuerdo al artículo 76, independientemente de si ellos se insertan dentro del Poder Judicial o no — verbigracia: la justicia electoral—.

Más en detalle, cuando se trata de precisar quién ejerce la función administrativa, el artículo 24 de la CPR responde que esta está radicada en el presidente de la república, quien la ejerce con la colaboración de 
los órganos que establece la Constitución y de acuerdo a las leyes. Esto conforma lo que se conoce como la administración del Estado, la cual está integrada por los ministerios, las intendencias, las gobernaciones y los órganos y servicios públicos creados para el cumplimiento de la función administrativa, en donde destacan la CGR, el Banco Central, las Fuerzas Armadas y las Fuerzas de Orden y Seguridad Pública, los gobiernos regionales, las municipalidades y las empresas públicas creadas por ley. Todo esto de acuerdo al artículo 1 (18575) o también llamado Ley Orgánica Constitucional de Bases Generales de la Administración del Estado (LOCBGAE).

La CPR encomienda, por su parte, el ejercicio de la función jurisdiccional a órganos que toman el nombre de tribunales, sean ellos unipersonales o colegiados. Dichos tribunales son órganos del Estado, creados por la Constitución o las leyes. Solamente en el capítulo VI de la Constitución se utiliza la denominación «poder» y lo hacen para referirse a la organización de los tribunales ordinarios que ejercen la función jurisdiccional —el Poder Judicial —. Ello hace significar, precisamente, la importancia de esta organización estatal y de la función que desempeña: se trata del imperium que permite disponer de una situación jurídica subjetiva, que es objeto de un litigio, al hacer vinculante para esas partes la decisión unilateral e imperativa que adopte el órgano jurisdiccional ${ }^{2}$, de un modo definitivo e inmodificable.

La función jurisdiccional se distribuye en Chile en cuatro grandes órdenes: (i) los tribunales del Poder Judicial, ya sean ordinarios (tribunales de letras) o especiales (tribunales de familia, del crimen, del trabajo, de contratación pública, etcétera), y cuya competencia se extiende al conocimiento de las causas civiles y criminales, sin dejar de incluir las controversias de las que es parte la administración; (ii) la justicia electoral, integrada por un tribunal calificador de elecciones y por tribunales electorales regionales, con competencia en materia de escrutinio general y calificaciones de elecciones del presidente de la república, de los diputados y de los senadores; (iii) la justicia político-constitucional, a cargo del senado, en cuanto es el tribunal que conoce de las acusaciones constitucionales de la cámara de diputados en contra de las más altas autoridades del país por las infracciones y delitos constitucionales tipificados en el artículo 52, numeral 2, de la CPR; y (iv) el Tribunal Constitucional.

El artículo 76.1 de la CPR prescribe que en los tribunales establecidos por la ley descansa exclusivamente la facultad de conocer de las causas civiles y criminales, de resolverlas y de hacer ejecutar lo juzgado. A renglón seguido, y como natural corolario del principio de separación de 
poderes, preceptúa que ni el presidente de la república ni el congreso pueden, en caso alguno, ejercer funciones judiciales, avocarse causas pendientes, revisar los fundamentos o contenidos de sus resoluciones o hacer revivir procesos fenecidos.

La redacción de las normas constitucionales permite colegir que en ellas subyace el principio de división de poderes o de separación de funciones de manera más estricta que en lo que respecta a las vinculaciones funcionales entre el presidente de la república y el congreso nacional en materia de dictación de leyes: a ninguno de estos dos últimos les está permitido ejercer la función de los tribunales de justicia o revisar sus resoluciones.

Precisamente, debido a que solo los tribunales pueden ejercer jurisdicción, pesa en ellos un deber inherente, que se plasma en el principio de inexcusabilidad. El artículo 76.2 de la CPR dispone que «reclamada su intervención en forma legal y en negocios de su competencia, no podrán excusarse de ejercer su autoridad, ni aun por falta de ley que resuelva la contienda o asunto sometidos a su decisión.» De la disposición transcrita, resulta una cuestión de importancia que la ausencia de ley decisoria litis no permite excusar al juez de ejercer sus funciones.

\section{FUNCIÓN ADMINISTRATIVA}

Es necesario precisar el contenido esencial de las funciones que está llamado a cumplir el gobierno y, en particular, la administración del Estado. La respuesta se encuentra en disposiciones del orden constitucional - Constitución y leyes orgánicas constitucionales propiamente como tales-.

En una visión decimonónica y propia de un Estado liberal, el artículo 24.2 de la CPR confiere al presidente de la república competencia en todo cuanto tiene por objeto la conservación del orden público en el interior y la seguridad externa de la república, de acuerdo con la Constitución y las leyes. Pero, el ámbito de acción del Presidente se extiende mucho más allá de estos límites: los artículos 111.2 y 115.1 de la CPR refieren que, a nivel de las regiones en que se divide el territorio del país, la función administrativa tiene por objeto el desarrollo social, cultural y económico de la región, y que debe observarse, como principio básico, la búsqueda de un desarrollo territorial armónico y equitativo. También, en el nivel local, constan señales precisas que permiten comprender la función administrativa. El artículo 118.4 de la CPR prescribe que la finalidad de las municipalidades es satisfacer las necesidades de la comunidad local y asegurar su participación en el progreso económico, social y cultural de la comuna. 
Luego, sobresale el artículo 3 (LOCBGAE), que impone a la administración el deber de atender las necesidades públicas en forma continua y permanente, así como fomentar el desarrollo del país a través del ejercicio de las atribuciones que le confiere la Constitución y la ley, y otras labores más como son las de aprobación, ejecución y control de políticas, planes, programas y acciones de alcance nacional, regional y comunal. A estos precisos efectos, la misma disposición legal indica que la administración del Estado debe observar los principios de responsabilidad, eficiencia, eficacia, coordinación, impulsión de oficio del procedimiento, impugnabilidad de los actos administrativos, control, probidad, transparencia y publicidad administrativas, y participación ciudadana en la gestión pública, a la vez que garantiza la debida autonomía de los grupos intermedios de la sociedad para cumplir sus propios fines específicos, sin dejar de respetar el derecho de las personas para realizar cualquier actividad económica en conformidad con la Constitución Política y las leyes.

¿Qué se puede sacar en limpio de las normas jurídicas transcritas? Que la función administrativa está radicada en el presidente de la república, quien la ejerce básicamente con la colaboración de una administración del Estado, y que dicha función comprende, sin querer ser exhaustivos, la conservación del orden público en el interior y la seguridad externa de la república, la atención de las necesidades públicas en forma continua y permanente, la aprobación, ejecución y control de políticas, planes, programas, acciones y medidas que fomenten el desarrollo social, cultural y económico a nivel nacional, regional y local, que estén sujetas a criterios de equidad y armonía, y que permitan a las personas tener una efectiva participación en dicho progreso económico, social y cultural.

Es evidente, entonces, que el ámbito natural donde actúa la administración es el de los intereses generales, cosa que no sucede con los órganos jurisdiccionales.

\section{FUNCIÓN JURISDICCIONAL}

La función jurisdiccional es el poder-deber de conocer y resolver, por medio del proceso y con efecto de cosa juzgada, los conflictos de interés de relevancia jurídica que se promueven en el orden temporal dentro del territorio de la república ${ }^{3}$, a fin de, con ello, favorecer la paz social. En cuanto los tribunales ejercen unas potestades públicas de tipo jurisdiccional, ellas son parte necesaria del dominio de la ley ${ }^{4} \mathrm{o}$ de los tratados internacionales 5 . 
Es innegable que los tribunales de la república, donde se incluye a los del Poder Judicial, deben ser independientes, y que dicha independencia debe extrapolarse tanto al juez mismo como al órgano jurisdiccional en su integridad. Dicha independencia, a su turno, se difumina respecto de toda persona que ocurra ante un tribunal, así como respecto de cualquier otro órgano público, sea de rango constitucional o legal. Porque la legitimidad de las decisiones de los jueces no proviene ni de su forma de integración ni de los procesos de toma de decisión. En realidad, todo pasa por el apego que muestran al Derecho positivo. Esto es, a la Constitución y a las normas dictadas conforme a ella (artículo 6 de la CPR). La imposición de este deber supremo constituye también un elemento de garantía de la independencia e imparcialidad de los jueces: ellos no deben resolver los casos que conocen poniendo atención a las opiniones del Ejecutivo o del parlamento, ni tampoco buscar hacerse «populares» frente a la población. Los tribunales son, como dice Philippe Jestaz, un puro instrumento del Derecho, así como los partidos políticos son un puro instrumento de la acción política ${ }^{6}$, y la administración del Estado sería un puro instrumento de los intereses generales.

El vínculo que existe entre los tribunales y los órganos legislativos se halla en la principalísima función de dirección que cumple la ley para la creación jurisprudencial de los jueces, y no en el sentido de poder «corregir» las decisiones judiciales — para eso están los procedimientos recursivos e impugnaticios de tipo jurisdiccional, ya que, de otro modo, se infringe el principio de distribución de competencias-, sino para legitimarlas y encaminarlas conforme al sentido de la voluntad legislativa expresada en la ley, la cual obligatoriamente debe aplicar en la sentencia. Todo lo contrario ocurre al vincular tribunales con el Poder Ejecutivo: aquí prima la idea de que el juez debe ejercer una función de protección jurídica frente a lo actuado o dejado de actuar por la administración y, específicamente, en lo que respecta a la ejecución de la ley - por vía del reglamento- - y su aplicación a un caso concreto - por vía del acto administrativo- . El juez se vale, entonces, de la voluntad del legislador para tomar partido, y aceptar o rechazar lo que el gobierno y la administración deciden.

Con todo, y a diferencia de lo que sucede con el parlamento, con el presidente de la república y con la administración del Estado, los tribunales no tienen la capacidad de ejercer sus funciones mediante la formulación de una voluntad propia que no sea la del Derecho ${ }^{7}$ y que no esté directamente motivada por la acción de una parte legitimada - el actor-. Si se trata, por tanto, de buscar la fuente de legitimidad del ejercicio de poder público que detenta el juez, esta no es sino la voluntad 
que manifiesta el actor en su demanda y la del demandado en su contestación ${ }^{8}$. Es decir, para que la decisión de un juez no pueda ser politizada, debe exigirse del actor que su demanda presente un caso concreto, que constituya un problema personal del demandante, y que no sea generalizable hacia toda la comunidad?.

El ámbito de acción de la función jurisdiccional no está puesto, por tanto, en los intereses generales, sino en los derechos subjetivos, intereses legítimos y posiciones jurídicas que manifiestan los litigantes en el proceso.

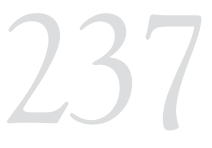

¿EXISTEN EN CHILE PROCEDIMIENTOS ADMINISTRATIVOS QUE PRESENTAN, TAMBIÉN, UNA NATURALEZA JURISDICCIONAL?

ARETHERE

ADMINISTRATIVE PROCEDURES THAT ALSO HAVE A JURISDICTIONAL NATURE IN CHILE?

tivo son esencialmente diversas, puesto que la finalidad de uno y otro es también distinta. Bastará lo que comentaremos en las líneas siguientes acerca del procedimiento administrativo en Chile para que el lector pueda concluir que su estructura y regulación distan de ser de naturaleza jurisdiccional.

Desde el año 2003, nos rige la ley 19.880, la cual establece bases de los procedimientos administrativos que rigen los actos de los órganos de la administración del Estado (LBPA). Esta ley provocó en el país un terremoto de magnitud. Se pasó, de un día a otro - pero con más de sesenta años de retraso- desde un proto-administrativismo a la modernidad. De haber conocido solamente el «procedimiento administrativo de primera generación», se abrió de par en par el portalón de una nueva estructura legal que consagraría un "procedimiento administrativo de segunda generación» y, además, asentaría ideas básicas para la formulación de "procedimientos administrativos de tercera generación»"

Si pudiéramos resumir el contenido de la LBPA, comenzaríamos por señalar que en ella se plasman los «principios del procedimiento administrativo»: escrituración, celeridad, economía procedimental, no formalización, gratuidad, conclusividad, contradictoriedad, imparcialidad, abstención, inexcusabilidad, impugnabilidad, y transparencia y publicidad. Se trata de verdaderas propiedades normativas destinadas a integrar regulativamente - es decir, no de manera simplemente explicativa ni supletoria - las actuaciones que se llevarán a cabo en cada procedimiento y para la sustentación de estos. 
La LBPA reconoce que en cualquier procedimiento administrativo actúan personas, las cuales toman la condición de «interesados» que se agrupan en alguna de las tres siguientes categorías: (i) las personas que promuevan el procedimiento administrativo como titulares de derechos o intereses individuales o colectivos; (ii) las personas que sin haber iniciado el procedimiento administrativo tengan derechos que puedan resultar afectados por la decisión que en el mismo se adopte; y (iii) las personas que no invocan un derecho, sino solamente intereses de carácter individual o colectivo, y que pueden resultar afectados por la resolución o el acto administrativo terminal y, por lo tanto, se apersonan en el procedimiento en tanto no haya recaído en él resolución definitiva.

La capacidad administrativa es algo más amplia que la civil, ya que para la LBPA también constan de suficiente capacidad como para actuar como «interesados» los menores de edad — en tanto se trate del ejercicio y la defensa de sus derechos e intereses, cuya actuación esté permitida por el ordenamiento jurídico-administrativo sin la asistencia de la persona que ejerza la patria potestad, tutela o curatela-. Asimismo, los interesados pueden actuar ante la administración personalmente o representados por medio de un tercero, que viene a llamarse apoderado, y que tiene todas las facultades necesarias para la consecución del acto administrativo, salvo manifestación expresa en contrario, según el artículo 22. De igual forma, el interesado puede ser asistido por un asesor en defensa de sus intereses cuando lo considere conveniente, según el artículo 11. Este asesor, letrado o no, puede identificarse con la misma persona a quien se ha designado como apoderado.

Los interesados tienen derechos que están expresamente reconocidos por la ley: (i) conocer, en cualquier momento, el estado de la tramitación de los procedimientos en los que tengan la condición de interesados, y obtener copia autorizada de los documentos que rolan en el expediente y la devolución de los originales, salvo que, por mandato legal o reglamentario, estos deban ser acompañados a los autos a su costa (artículo 17, a); (ii) identificar a las autoridades y al personal al servicio de la administración, bajo cuya responsabilidad se tramiten los procedimientos (artículo 17, b); (iii) eximirse de presentar documentos que no correspondan al procedimiento o que ya se encuentren en poder de la administración (artículo 17, c); (iv) acceder a los actos administrativos y a sus documentos en los términos previstos en la ley (artículo $17, \mathrm{~d})$; (v) ser tratado con respeto y deferencia por las autoridades y funcionarios, quienes habrán de facilitarles el ejercicio de sus derechos y el cumplimiento de sus obligaciones - vale recalcar que los actos de instrucción que requieran la intervención de los interesados habrán de practicarse en la forma que resulte más cómoda para ellos y sea compatible, en la medida de lo posible, con sus obligaciones laborales o profesionales (artículo 17, e)—; (vi) formular alegaciones y aportar 
documentos en cualquier fase del procedimiento anterior al trámite de audiencia, los cuales deberán ser tenidos en cuenta por el órgano competente al redactar la propuesta de resolución (artículo 17, f); (vii) exigir las responsabilidades de la administración pública y del personal a su servicio, cuando así corresponda legalmente (artículo 17, g); (viii) obtener información acerca de los requisitos jurídicos o técnicos que las disposiciones vigentes impongan a los proyectos, y de las actuaciones o solicitudes que se propongan realizar (artículo 17, h); y (ix) cualesquiera otros que les reconozcan la constitución y las leyes (artículo 17, i). Los interesados tienen, por último, el derecho de provocar la sustanciación de un procedimiento administrativo, cosa que realizarán a través de una «solicitud» (artículo 30, 10).

La LBPA se encarga luego de regular pormenorizadamente el íter del procedimiento general. Para esto, hay algunas fases: (i) una etapa de iniciación, que puede ser de oficio o a solicitud de interesado (artículo 28); (ii) una fase de instrucción, en la que la administración debe determinar, conocer y comprobar los hechos sobre los cuales se pronunciará en definitiva, dándole oportunidad al interesado para allegar sus propias defensas y pruebas, y para proponer otras actuaciones o diligencias a ese efecto; (iii) una última etapa de finalización que, como su nombre lo indica, es el momento en que, por regla general, se manifiesta la voluntad orgánica administrativa constitutiva de un acto administrativo terminal, o, como lo señaló el mensaje del presidente de la república, esta etapa «corresponde al período en que se manifiestan los actos pedidos o requeridos, que ya han sido debidamente analizados en sus antecedentes y efectos».

La LBPA dispone que la decisión administrativa terminal debe cumplir ciertos estándares mínimos. Estos son: (i) decidir las cuestiones de fondo que fueron objeto del procedimiento, así como las cuestiones conexas al mismo; (ii) la decisión debe ser congruente y mesurada; (iii) la decisión administrativa debe ser fundada; (iv) la decisión debe expresar los recursos que procedan en su contra, el órgano administrativo o judicial ante el que hubieran de presentarse y el plazo para interponerlos; y (v) la decisión no debe agravar la situación inicial del interesado cuya solicitud ha dado motivo o iniciado el procedimiento de que se trata.

No obstante que la dictación del acto administrativo terminal pone fin al procedimiento administrativo, la ley establece que siempre será necesario, antes de ejecutar válidamente un acto administrativo, ponerlo en conocimiento de su destinatario. En el capítulo III de la LBPA (artículos 45 a 49) se regula acerca de la comunicación y ejecutividad del acto administrativo al unísono, con lo que se da a entender que no ha nacido a la vida del Derecho aquel acto administrativo que, no obstante, haber 
pasado por todas las etapas gestacionales del procedimiento administrativo, no es comunicado de la forma como establece la ley.

Por último, la LBPA se ocupa con algún detalle acerca de la extinción y revisión de los actos administrativos, de una manera que se distancia de la revisión jurisidiccional propiamente tal. Se regulan las formas de extinguir o modificar un acto administrativo por razón de ilegalidad o mérito, a través de la dictación de un nuevo acto de la administración -invalidación y revocación, respectivamente-, y de los recursos administrativos ordinarios — reposición y jerárquico- y extraordinarios - recurso de revisión-. Es decir, si bien los actos administrativos buscan ser funcionales a una necesaria estabilidad que pueda otorgar certeza jurídica a los destinatarios, lo cierto es que no alcanzan a gozar de una verdadera fuerza de cosa juzgada.

Adicionalmente, se sanciona el derecho de toda persona de pedir la revisión de lo actuado y decidido por la administración, conforme al principio de dualidad de vías impugnaticias del ciudadano — sede administrativa y sede jurisdiccional-. Salvo casos especiales contemplados en la ley, en los que se exige, necesariamente, que se agote previamente la vía recursiva administrativa antes de que quede el interesado procesalmente habilitado para ocurrir o reclamar ante los tribunales (verbigracia, reclamos de ilegalidad municipal y de los gobiernos regionales) ${ }^{11}$, a los ciudadanos siempre les queda abierta la posibilidad de utilizar indistintamente la vía judicial o la administrativa.

Si el interesado prefiere la vía impugnaticia administrativa, el recurrente debe primeramente esperar la resolución de su recurso por parte de la administración o el transcurso del plazo - para deba entenderlo desestimado - antes de deducir igual pretensión ante los tribunales (artículo 54.1 de la LBPA). Por su parte, si el interesado utiliza derechamente la vía jurisdiccional, entonces cualquiera reclamación administrativa que luego él haga respecto del mismo acto, inhabilita a la administración de conocerla (artículo 54.3 de la LBPA). En todo caso, con el objeto de no desmejorar los derechos y las acciones de ese interesado, el artículo 54.2 dispone que, planteada la reclamación en sede administrativa, se interrumpirá el plazo para ejercer la acción jurisdiccional, y este volverá a contarse desde la fecha en que se notifique el acto que la resuelve o, en su caso, desde que la reclamación se entienda desestimada por el transcurso del plazo. 


\section{PROCEDIMIENTOS ADMINISTRATIVOS DE PRIMER GRADO: DE TIPO SANCIONATORIOS, EL DEBIDO PROCESO Y LA NEGACIÓN DE LAS POTESTADES RESOLUTIVAS DE LA ADMINISTRACIÓN}

Desde hace ya largos años, y basado en la labor desplegada por el Tribunal Constitucional, se ha consolidado en nuestro medio la idea de que a los procedimientos sancionatorios de la administración —si bien quedan sujetos en forma estricta a las regulaciones legales administrativas pertinentes, al tratarse del ejercicio del mismo ius puniendi del Estadoles es exigible el respeto a los principios inspiradores del orden penal contemplados en el artículo 19, numeral 3, de la CPR ${ }^{12}$.

Las reglas del debido proceso aplicadas a los procedimientos administrativos sancionadores han infiltrado a estos últimos con ideas normativas básicas y garantistas,. Estas son las siguientes: (i) las sanciones dispuestas por la administración no pueden cumplirse mientras no se encuentren ejecutoriadas (STC 1518-09-INA); (ii) los apremios que importen una privación de la libertad deben llevarse a cabo con plena observancia de las garantías establecidas en el artículo 19, numeral 7 de la CPR —el arresto solo puede ser decretado cuando una ley lo prescriba, mediante una orden expedida por un funcionario público facultado para hacerlo y previa intimación legal de la misma (STC 519, 576 y 1006)—; (iii) el legislador siempre debe establecer las garantías de un proceso racional y justo; (iv) oportuno conocimiento de la acción y debido emplazamiento; (v) bilateralidad de la audiencia; (vi) aportación de pruebas pertinentes y derecho a impugnar lo resuelto por un tribunal imparcial e idóneo, y establecido con anterioridad por el legislador (STC 481); (vii) garantizar la proporcionalidad de las medidas adoptadas en virtud de un procedimiento sancionador (STC 1518-09-INA); (viii) asimismo, la persona debe recibir el trato de quien se presume que es inocente, porque ello es concreción de la dignidad de la persona humana y del derecho a la defensa efectiva ${ }^{13}$; entre otros más.

Las sentencias del Tribunal Constitucional no trasuntan la idea de que los procedimientos administrativos sancionadores sean de tipo jurisdiccional. Antes bien, acudiendo a la CPR, el tribunal trata de dotarlos de un estándar de garantía mínima para la persona que es objeto de ellos.

$\mathrm{Al}$ mismo tiempo, la justicia constitucional ha ratificado la idea de una «reserva judicial», lo que viene a significar que, en estas materias, siempre tendrán los tribunales —y no la administración — la última palabra. A este efecto, el tribunal ha declarado inaplicables por inconstitucionales antiguas disposiciones legales que restringían el acceso a la jurisdicción

¿EXISTEN EN CHILE PROCEDIMIENTOS ADMINISTRATIVOS QUE PRESENTAN,

TAMBIÉN, UNA NATURALEZA JURISDICCIONAL?

\section{ARETHERE}

ADMINISTRATIVE PROCEDURES

THAT ALSO HAVE A JURISDICTIONAL NATURE IN CHILE? 
a través del añejo solve et repete, puesto que eran barreras injustificadas y carentes de razonabilidad al derecho a la justicia ${ }^{14}$. Citamos:

Que cabe tener especialmente presente que el objeto del reclamo judicial es la multa cursada, reclamo que persigue eximir al administrado del pago de la misma, por entenderla contraria a derecho, y que el requisito establecido por el legislador para hacer valer dicha pretensión ante el órgano jurisdiccional es el cumplimiento íntegro de dicha sanción. La identificación entre objeto reclamado y condictio sine qua non para la admisibilidad del reclamo, lleva, en los hechos, a que el acto administrativo por el cual se cursa la multa sea inimpugnable, en términos que no obstante poder formalmente reclamarse en contra del mismo, este produce todos sus efectos, y aun en el caso de una ilegalidad flagrante, evidente y manifiesta, el administrado debe soportarla sin que la ley establezca mecanismo alguno que suspenda el cumplimiento de la sanción y a la vez habilite a reclamar de la misma. En esa perspectiva, la obligación de pagar toda la multa antes de impugnarla hace que la tutela judicial sea tardía e inoportuna, pues la lesión jurídica al interés del administrado por causa de una ilegalidad se produjo, ya generó sus efectos, y la sanción que de dicha lesión derivó fue cumplida, lo que transforma a la acción judicial de reclamo en un mero proceso de reembolso condicionado a la juridicidad de la multa ya pagada ${ }^{15}$.

En ligamen con lo anterior, la LBPA ha cumplido una función educadora en la doctrina y jurisprudencia judicial al poner orden en cuestiones que hasta hace pocos años eran tremendamente debatidas en el medio nacional. En efecto, por largo tiempo, las cortes de apelaciones y la misma Corte Suprema calificaron como un «indebido ejercicio de función jurisdiccional» algo que era y es de la esencia de la administración; a saber, decidir sobre el interés general aplicado a casos concretos, e incidir en posiciones jurídicas de los administrados. Esas cortes, conociendo de acciones de amparo de derecho fundamentales («recurso de protección», artículo 20 de la CPR), resolvieron que la administración no tenía facultad para adoptar decisiones declarativas de derechos de las personas ni para interpretar normas jurídicas ni, tampoco, para calificar actos entre privados aun cuando ellos estuvieren sujetos al control de la administración. Básicamente, las resoluciones judiciales se dictaron en contra de la Dirección del Trabajo y de otros servicios públicos fiscalizadores (verbigracia: superintendencias), cuando ejercían sus funciones legales de control, supervisión y sanción ${ }^{16}$. 
En lo medular, los más altos tribunales del país, entendieron que en todas esas oportunidades, la administración terminaba sustituyendo a los tribunales, únicos llamados a declarar el derecho y a interpretar la ley. Las altas cortes de justicia razonaron que, en la especie, el ciudadano afectado era objeto de un juzgamiento por una «comisión especial» no por el tribunal que señalaba la ley, lo que infringía el artículo 19, numeral 3 , inciso 4 de la CPR. De este modo, las sentencias judiciales terminaron dejando sin efecto lo decidido por la administración.

Pues bien, afortunadamente la LBPA materializó una verdadera sistematización teórica y sustantiva del acto administrativo. A partir de su artículo 3, se lo puede definir como «una decisión formal que emite un órgano de la Administración del Estado, en el que se contienen declaraciones de voluntad, de dictamen o de juicio, constancia o conocimiento, y que se realiza en el ejercicio de una potestad pública o dentro de la competencia que le ha atribuido la Constitución Política de la República (CPR) o la ley».

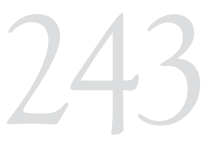

¿EXISTEN EN CHILE PROCEDIMIENTOS ADMINISTRATIVOS QUE PRESENTAN, TAMBIÉN, UNA NATURALEZA JURISDICCIONAL?

ARETHERE

ADMINISTRATIVE PROCEDURES

THAT ALSO HAVE A JURISDICTIONAL NATURE IN CHILE?

Por lo mismo, y en cuanto se trata de una declaración de voluntad, el acto administrativo contiene una decisión orgánica administrativa. En otras palabras, la declaración expresa una decisión administrativa que puede contener una orden o un mandato, o una opinión o un informe y, por lo mismo, es del todo evidente que la administración puede, del mismo modo, decidir la cuestión que es objeto del procedimiento administrativo, al declarar derechos, reconocer posiciones jurídicas, enjuiciar eventos o al poner la información que obra en su poder a disposición del solicitante. En estos supuestos, la administración no está sustituyendo a los jueces ni tampoco está ejerciendo función jurisdiccional, toda vez que lo que ella decida jamás será la última palabra, al no gozar el acto administrativo de la fuerza de la cosa juzgada.

\section{PROCEDIMIENTOS ADMINISTRATIVOS DE SEGUNDO GRADO: LA CONFUSIÓN RESPECTO DE SI LA VÍA RECURSIVA ANTE LA PROPIA ADMINISTRACIÓN TIENE O NO NATURALEZA JURISDICCIONAL}

a. Diversas leyes administrativas consagran vías impugnaticias especiales en contra de decisiones de órganos administrativos, cuya regulación procedimental consagra primero una vía recursiva ante la propia autoridad administrativa y, luego, ante los tribunales de justicia. Estas son las siguientes:

- Debido a una deficiente terminología utilizada por el legislador - mucha de ella importada indiscriminadamente del derecho anglosajón, donde es habitual que órganos administrativos (agencies) actúen de modo cuasi-jurisdiccional- ha resultado 
para una parte de la doctrina chilena que algunas reclamaciones que se inician en sede administrativa constituirían el ejercicio de funciones jurisdiccionales para los órganos administrativos que conocen de ellas «en primera instancia». Los ejemplos más paradigmáticos son el director regional del Servicios de Impuestos Internos (SII), el director de aduanas y el ministro de transportes y telecomunicaciones.

- En el primer caso, dentro del libro III del Código Tributario, intitulado «De los tribunales, de los procedimientos y de la prescripción», los artículos 115.1, 119 y 120 establecían que los directores regionales del SII conocerían, en primera o en única instancia — según fuese el caso— las reclamaciones de los contribuyentes, mientras que las cortes de apelaciones conocerían, en segunda instancia, los recursos de apelación que se dedujeran contra las resoluciones de dichos directores regionales. A lo anterior se sumaba la circunstancia de que los artículos 134, 136 y siguientes del mismo código referían acerca de la «sentencia de primera instancia», del «fallo de primera instancia» o de la «sentencia que falle el reclamo», todas ellas dictadas por el mismo director regional o «juez tributario» y en posición de ser objeto de «apelaciones» $\mathrm{O}$ «recursos de apelación» ante la corte respectiva. Con esta terminología, no podía extrañar que la Corte de Santiago entendiera que «[...] una liquidación del SII en la que se determinan diferencias de tributos a un contribuyente, hace las veces de demanda», así como que:

[...] atento al carácter de demanda que importa una liquidación como la anteriormente descrita, su notificación no envuelve, de consiguiente, un acto meramente administrativo sino que de connotación jurisdiccional, como quiera que permitirá al notificado, dentro del plazo legal, deducir reclamación o invocar otros derechos en contra de la liquidación que se ha puesto legalmente en su conocimiento, es decir, «dar contestación a la demanda» que le afecta a su patrimonio, iniciándose de esa manera el juicio contencioso administrativo» (Corte de Santiago, 15 de diciembre de 1980, nahum con SII).

- Es evidente que a los órganos administrativos — como es el caso de los directores regionales del SII- aun cuando la ley orgánica respectiva les otorgase la función de actuar como «tribunal tributario», realmente no los convertía en tales ni a sus titulares en verdaderos jueces. A ellos les faltó siempre la debida independencia e imparcialidad, la cual es propia del sentenciador en un verdadero Estado de Derecho, ya que su estabilidad en el empleo siempre estaba condicionada a tener la confianza del director nacional del SII, cargo que, a su 
turno, era de confianza exclusiva del presidente de la república. Es decir que no solamente estaban obligados por el Derecho cuando decidían reclamos, sino que también les obligaban los dictámenes del mismo director nacional, quien era su jefe.

- Afortunadamente, el caso del «tribunal tributario» —y lo mismo ocurrió respecto del «tribunal aduanero»- fue resuelto con la ley 20.322 de 2009 (Ley Orgánica de Tribunales Tributarios y Aduaneros), en la que estas funciones fueron entregadas a verdaderos jueces especiales, designados por el presidente de la república a propuesta de las ternas que preparan las cortes de apelaciones, aquellas que permanecen en sus cargos durante su buen comportamiento y que solamente están obligadas en sus funciones por la ley.

- El tercer ejemplo, sin embargo, todavía presenta problemas. Nos referimos al ministro de transportes y telecomunicaciones; específicamente, cuando le toca informarse de la reclamación del artículo 36a de la Ley General de Telecomunicaciones (18.168). Por el artículo 36 de este cuerpo legal, se dispone que las infracciones serán sancionadas por el ministro. Por su parte, el artículo 36a establece que el procedimiento debe sustanciarse al efecto, y que se contempla una formulación de cargos al infractor que hace la subsecretaría de telecomunicaciones, así como un término de prueba si existen hechos sustanciales, pertinentes y controvertidos, y, finalmente, existe una etapa de resolución. Si en dicha resolución se aplica una sanción, la disposición legal prescribe que ella es apelable para ante la Corte de Apelaciones de Santiago, a menos que se decrete la caducidad de una concesión de telecomunicación, en cuyo caso la apelación se hará para ante la Corte Suprema. Esta apelación debe ser fundada e interponerse dentro de los diez días siguientes a la fecha de notificación de la resolución.

- Ante la pregunta sobre si el artículo 36a de la ley 18.168 regula un procedimiento administrativo o uno de carácter jurisdiccional, existe uniformidad en el medio nacional de que se trataría de un procedimiento jurisdiccional en sede administrativa. Primeramente, debe comentarse que, durante la tramitación legislativa de esta norma, en el senado se presentó una indicación tendente a reemplazar las expresiones «apelable» $\mathrm{y}$ «apelación» por «reclamable»y «reclamación», respectivamente, con la finalidad de evitar una probable confusión de parte del ministro de transportes y telecomunicaciones en un tribunal. Estas indicaciones fueron rechazadas, lo que facilitó, entonces, que se considere que el proceso del artículo 36a es jurisdiccional y que el ministro es verdaderamente un juez. 
- A lo anterior se sumaron ciertos pronunciamientos administrativos y jurisdiccionales que reforzaron la errada tesis. Por ejemplo, en el dictamen 3.068 de 2003, la CGR reconoció aquella singularidad, y consideró que el ministro de transportes y telecomunicaciones es el tribunal de primera instancia, y los tribunales superiores de justicia eran la segunda instancia, por lo cual la misma CGR se declaró incompetente para revisar la legalidad de dicho proceso - aplica artículo 6.3 ley 10.336 de CGR: «la contraloría no intervendrá ni informará los asuntos que por su naturaleza sean propiamente de carácter litigioso, o que estén sometidos al conocimiento de los tribunales de justicia, que son de la competencia del consejo de defensa del estado, sin perjuicio de las atribuciones que, con respecto a materias judiciales, reconoce esta ley al contralor»—. También, la Corte de Santiago ha afirmado el carácter jurisdiccional del proceso sancionatorio del artículo 36a. En octubre de 2010, declaró que $«[\ldots]$ el negocio sub lite incide en un procedimiento jurisdiccional en sede administrativa [...]» (rol 4703). Y, en otra sentencia de agosto del mismo año, había señalado que «[...] tratándose en la especie de una instancia jurisdiccional en sede administrativa $[. .]$.$» no resultaban aplicables las normas de ca-$ rácter administrativo en su procedimiento (rol 7960).

- En nuestra opinión, los pronunciamientos de la CGR y la Corte de Santiago afectan el Estado de Derecho chileno, puesto que nos están diciendo que puede fungir de «juez» una autoridad administrativa, colaboradora directa del presidente de la república en las funciones de gobierno y administración, y que no goza de independencia - ni orgánica, ni funcional ni personal- ni de inamovilidad en su cargo, además de que, por último, tampoco tiene mínimas garantías de actuar imparcialmente, pues obedece las órdenes e instrucciones del presidente y porque, cuando sanciona por virtud del artículo 36a, está juzgando en causa propia, debido a que es un órgano dependiente del mismo que se inserta dentro del organismo que dirige el ministro, el que hace la formulación de cargos en contra del particular afectado - la subsecretaría de telecomunicaciones-.

- Como bien afirman Ferrada y Bordalí, «se viola el derecho a la tutela judicial cuando, por ejemplo, la ley le exige al ciudadano que concurra ante un órgano de la propia administración para que dirima un contencioso con ella misma» ${ }^{17}$. Este es, precisamente, el caso del ministro de transportes y telecomunicaciones. 


\section{VII.CASOS PACÍFICOS DE ÓRGANOS ADMINISTRATIVOS QUE EJERCEN JURISDICCIÓN}

Debemos dar cuenta, por último, de ejemplos excepcionales en los que es posible visualizar actividad jurisdiccional de parte de órganos administrativos. Nos referimos, por un lado, a los casos de la Superintendencia de Valores y Seguros y de la Superintendencia de Salud y, por el otro, a la CGR. En el primer caso, se trata de órganos administrativos a los que la ley les otorga especialmente la atribución, bajo ciertas circunstancias, de actuar como árbitros, mientras que en el caso de la CGR, se trata de una atribución que recibe directamente de la Constitución en materia de conocimiento y juzgamiento de las cuentas que deben dar las personas que manejan o administran los recursos públicos.

\section{VII.1. Órganos administrativos que pueden actuar como árbitros arbitradores}

El artículo 3, letra i, del decreto con fuerza de ley 251 de 1931, sobre compañías de seguros, sociedades anónimas y bolsas de comercio otorga a la Superintendencia de Valores y Seguros atribuciones especiales para:

[...] resolver, en casos a su juicio calificados, en el carácter de árbitro arbitrador sin ulterior recurso, las dificultades que se susciten entre compañía y compañía, entre estas y sus intermediarios o entre estas o el asegurado o beneficiario en su caso, cuando los interesados de común acuerdo lo soliciten. Sin embargo, el asegurado o el beneficiario podrán por sí solos solicitar al árbitro arbitrador la resolución de las dificultades que se produzcan, cuando el monto de la indemnización reclamada, no sea superior a 120 unidades de fomento.

De igual manera, el artículo 117 del decreto con fuerza de ley 1, de 2005, otorga a la Superintendencia de Salud —actuando a través del Intendente de Fondos y Seguros Previsionales de Salud — la calidad de árbitro arbitrador resolviendo las controversias que surjan entre las instituciones de salud previsional o el Fondo Nacional de Salud y sus cotizantes o beneficiarios, siempre que queden dentro de la esfera de supervigilancia y control que le compete a la Superintendencia de Salud, y sin perjuicio de que el afiliado pueda optar por recurrir a la justicia ordinaria.

En los casos reseñados, como bien se advertirá, la autoridad administrativa que hace de árbitro arbitrador no resuelve sobre «negocio propio», sino que se pronuncia acerca de una controversias entre dos personas independientes y ajenas del todo a la entidad administrativa actuando en función jurisdiccional. Por ello, estos casos no provocan crítica de parte de la doctrina nacional.

Las normas procesales a que se sujetan los juicios arbitrales que sustancian las Superintendencia de Valores y Seguros y de Salud tampoco se

¿EXISTEN EN CHILE PROCEDIMIENTOS ADMINISTRATIVOS QUE PRESENTAN

TAMBIÉN, UNA

NATURALEZA

JURISDICCIONAL?

ARETHERE

ADMINISTRATIVE PROCEDURES

THAT ALSO HAVE A JURISDICTIONAL NATURE IN CHILE? 
identifican con normas procedimentales administrativas, por lo que la LBPA no se aplica en forma directa ni indirecta. Por el contrario, esos procesos se regulan por normas de tipo jurisdiccional, sea de aquellas que se dan o aquellas en las que convienen las mismas partes litigantes ${ }^{18}$ o son establecidas por la ley o el árbitro ${ }^{19}$.

\section{VII.2. La CGR y el juicio de cuentas}

El artículo 98.1 de la CPR confiere a la CGR una especial función de tipo jurisdiccional. A saber, la de «juzgar» las cuentas de las personas que tengan a su cargo bienes del fisco, de las municipalidades y de los organismos y servicios que determinen las leyes. La persona obligada a rendir cuenta puede ser un funcionario público o, también, una persona o entidad privada que tiene —o ha tenido— a su cargo la percepción o la recaudación, la custodia, la administración, el pago y la inversión de fondos del fisco, de las municipalidades, de la beneficencia pública y de otros servicios que determinen las leyes.

El examen de las cuentas tiene como objetivos: (i) fiscalizar la percepción de las rentas del fisco o de las demás entidades sometidas a la fiscalización de la Contraloría General de la República; (ii) fiscalizar la inversión de los fondos de esas corporaciones, y comprobar si en ambos casos se ha dado cumplimiento a las normas legales y reglamentarias que rigen su ingreso y su aplicación o gasto; (iii) y comprobar la veracidad y fidelidad de las cuentas, la autenticidad de la documentación respectiva y la exactitud de las operaciones aritméticas y de contabilidad. Por su parte, en el caso del examen de las cuentas que deben otorgar personas y entidades de carácter privado, la fiscalización de la inversión de los fondos públicos o fiscales que perciban aquellos por leyes permanentes - a título de subvención o aporte del Estado, para una finalidad específica y determinada - se limitará a establecer si se ha dado cumplimiento a dicha finalidad.

Si la cuenta no es encontrada conforme, se iniciará el «juicio de cuentas», cuya demanda estará integrada por el reparo de la cuenta. El reparo es la omisión de cualquiera de los requisitos señalados en los artículos 98 y 99 de la Ley Orgánica Constitucional de la Contraloria General de la República (LOCCGR) y, en general, conforma la omisión o el incumplimiento de cualquier disposición legal o reglamentaria — de fondo o de forma- que esté relacionada con la rendición de cuentas ${ }^{20}$.

En el juicio de cuentas se ejerce, en consecuencia, una acción contencioso-administrativa de defensa de recursos públicos, la cual es dirigida 
en contra de las personas que, habiendo manejado y tenido a su cargo dichos recursos, no hayan presentado la cuenta exigida por ley, o aquellas cuya cuenta presentada a revisión hubiere sido reparada por la Contraloría con la finalidad de declarar su responsabilidad civil en los hechos, de manera de obligarlas a la reparación del perjuicio que se hubiere irrogado al fisco, a las municipalidades o a otros organismos y servicios públicos personificados.

La LOCCGR radica esa función jurisdiccional en un tribunal de primera instancia, integrado por el subcontralor general y por un tribunal de segunda instancia, el cual conoce de los recursos de apelación y de revisión, y que, a su vez, está integrado por el contralor general — quien lo presidirá- y por dos abogados designados por el presidente de la república - a propuesta en terna del contralor general-. El tribunal de cuentas es, entonces, un órgano jurisdiccional que se encuentra incorporado dentro de la propia CGR, la cual, en su esencia, es un órgano administrativo llamado primeramente a ejercer funciones de control preventivo de legalidad en sede administrativa sobre los actos de la administración ${ }^{21}$. El juicio de cuentas es, de esta manera, la excepción de lo anterior: la revisión de legalidad se hace en sede jurisdiccional.

A consecuencia de lo recién afirmado, las reglas por las que se sustancia el juicio de cuentas no son administrativas, sino que consisten en regulaciones procesales. Es decir, de naturaleza jurisdiccional, y contempladas en los artículos 107 a 119 de la LOCCGR.

En lo medular, el juicio se inicia con una demanda que contiene el reparo de una cuenta, el cual es formulado por un jefe de la división o por el contralor regional, y del que se otorga traslado al cuentadante. Producida la contestación o, en su defecto, la rebeldía del cuentadante, el jefe del departamento informará el expediente dentro de treinta días. En seguida, el expediente será remitido al fiscal de la CGR, la cual será parte en este juicio como representante de los intereses del fisco o de las instituciones públicas afectadas, y deberá contestar dentro de un plazo de quince días al juzgado de cuentas. Simultáneamente, el juez de primera instancia abre un término de prueba de quince días, el cual es prorrogable si las circunstancias lo exigen. Luego de ello, el proceso queda en estado de sentencia, la que deberá ser dictada en un plazo de treinta días. Contra la sentencia de primera instancia las partes podrán entablar un recurso de apelación en el término fatal de quince días - contado desde su notificación-. El recurso será presentado al juez de cuentas ante el tribunal de segunda instancia, el cual se pronunciará en el plazo de treinta días, contados desde la concesión del recuso — después

21 El Tribunal de Cuentas, de primera y segunda instancia, en su calidad de órgano jurisdiccional, se encuentra sujeto a la Superintendencia Directiva, Correccional y Económica de la Corte Suprema (artículo 79.1 de la CPR). 
de oír al recurrente y al fiscal en la misma forma y plazos establecidos para la primera instancia-. Si el apelante no agregase a su presentación nuevos antecedentes, el tribunal de segunda instancia podrá resolver sin más trámite. Pero si en la apelación se ofreciere rendir pruebas que no hubieren podido rendirse en primera instancia, o se alegaren hechos nuevos, el tribunal de segunda instancia podrá — de oficio o a petición de parte- abrir un término especial de prueba que no podrá exceder de diez días.

\section{CONCLUSIONES}

La función administrativa está radicada en el presidente de la república y es ejercida con la colaboración de la administración del Estado. Al mismo tiempo, la función jurisdiccional está radicada en los jueces que integran cuatro distintos órdenes jurisdiccionales.

La diferenciación material de ambas funciones podría resumirse en que la administrativa es una actividad encausada hacia el futuro. Se trata de una actividad que es de tipo garantista, prestacional, conformadora, planificadora y fomentadora, y a cuyo efecto la administración debe mantener una persistente atención sobre los intereses generales y las condiciones fácticas sobre las cuales actúan las personas en busca del bien común y de su propia satisfacción personal. De este modo, casi siempre se puede volver sobre sus pasos adoptando decisiones y contradecisiones que insten del modo más perfecto por la creación de aquellas condiciones sociales que permitan a todos los integrantes de la comunidad nacional la mayor realización espiritual y material posible, como lo indica el artículo 1.4 de la CPR.

Los tribunales, por su parte, ejercen una función reactiva tendente a solucionar una controversia jurídica, de orden temporal, con lo que declaran el derecho de cada parte litigante. Esa decisión está sujeta a un sistema de control posterior más o menos reducido, que se expresa en recursos procesales ordinarios (verbigracia, apelación) o extraordinarios (verbigracia, casación), a resultas del cual, en determinado momento, lo decidido por la judicatura adquiere una cualidad que jamás adoptan las decisiones administrativas. Esta es la fuerza de la cosa juzgada, que protege, antes que al juez, lo que él ha decidido.

Se debe destacar, también, como diferenciación de funciones administrativas y jurisdiccionales, la circunstancia de que un juez, cuando ejerce jurisdicción, puede controlar desde un punto de vista estrictamente jurídico la manera como se ha ejercido la función administrativa ${ }^{22}$, pero los órganos de la administración del Estado jamás pueden juzgar a las 
decisiones de los jueces ${ }^{23}$. Esta es la directa consecuencia del principio de distribución de funciones.

Los órganos administrativos, por regla general, no están organizados de tal forma que les permita cumplir con funciones jurisdiccionales - conforme a un estándar mínimo propio de un Estado de Derecho-, pues les falta independencia, imparcialidad y ser inamovibles. Por lo mismo, gran parte de la función administrativa — aquella que se dedica a fiscalizar o controlar actividades de particulares y, si es del caso, sancionar las prácticas ilegales o constitutivas de infracciones administrativas- se rige por regulaciones administrativas, en las que el LBPA actúa como ley supletoria e integradora, y donde, a un mismo tiempo, la jurisprudencia del Tribunal Constitucional ha declarado uniformemente que deben cumplirse estándares básicos del debido proceso penal ${ }^{24}$.

Únicamente en casos muy excepcionales es posible visualizar órganos que ejercen jurisdicción y que, al mismo tiempo, integran el complejo orgánico que conocemos como administración del Estado ${ }^{25}$. Su aceptación por el medio nacional está dada porque, cuando la Constitución o la ley les atribuyen dicha función, ella se ejerce sobre conflictos que no son «propios» al respectivo organismo administrativo. En estos casos, esa función jurisdiccional se rige por reglas procesales, que no por regulaciones del procedimiento administrativo, y la LBPA no está llamada a cumplir un papel al respecto. 